\title{
Design, fabrication, and test of a sensor array for perspective biosensing in chronic pathologies
}

\author{
Andrea Cavallini*, Camilla Baj-Rossi, Sara Ghoreishizadeh, Giovanni De Micheli, Sandro Carrara \\ Integrated Systems Laboratory \\ Swiss Federal Institute of Technology (EPFL) \\ Lausanne, Switzerland \\ *Andrea.cavallini@epfl.ch
}

\begin{abstract}
Biosensing for chronic pathologies requires the simultaneous monitoring of different parameters such as drug concentrations, inflammation status, temperature and $\mathrm{pH}$. In this paper we discuss the design, fabrication and test of a sensor array hosting five biosensor platforms, a pH electrode and a temperature sensor. Different and reproducible nano-biofunctionalization can be obtained with high spatial resolution via selective electrodeposition of chitosan/MWCNT/enzyme solutions at the various electrodes. The array, completely fabricated with biocompatible materials, can be integrated with a CMOS integrated circuit and a remote powering coil for the realization of a fully implantable device.
\end{abstract}

Keywords - microfabrication; electrodeposition; biosensor; glucose; temperature; $\mathrm{pH}$; biocompatibility, personalized therapy

\section{INTRODUCTION}

Construction of fully implantable biosensors requires the integration of heterogeneous components, like electrodes for the recognition of the target compounds, a circuit capable to perform the measurements and to transmit the data $[1,2]$, and a power source. Moreover, material, dimensions and shape of the implant must be well tolerated by the host, in order to avoid toxicity and chronic inflammation. Promising prototypes have been developed for glucose, and validated up to 8 months in mice [3] and up to one year in pigs [4]. The next step will be the extension of this technology to different applications, such as drugs and inflammation detection in chronic pathologies.

Unfortunately, drugs and metabolites biosensing present several obstacles: first, concentrations of target compounds in the body are often in the -nano -micro molar range [5] and difficult to detect; second, the biosensors must be able to operate precisely in complex solutions, like plasma or interstitial fluid; third, the electrochemical measures are affected by local $\mathrm{pH}$ and temperature [6], that need to be constantly monitored in order to obtain reliable data.

To address these problems, modification of the electrode surface with carbon nanotubes resulted useful to improve sensitivity and detection limit [7,8], and proved necessary to sense physiological concentrations of analytes in human plasma [9]; while novel designs based on micro electrode arrays, can enhance the sensor performance, reducing background and capacitive current, and improving the diffusion of analytes at the interface $[10,11]$.

This research has been supported by different sources of founding Sinergia project CRSII2 127547/, and the i-IronIC project, financed with a grant from the Swiss Nano-Tera.ch initiative and evaluated by the Swiss National Science Foundation.
In this work we discuss the design, fabrication, functionalization and test of a sensor array hosting an electrochemical cell with five independent working microelectrodes, a temperature sensor and a $\mathrm{pH}$ sensor. Electrodes were selectively functionalized and enhanced towards the electrodeposition of a chitosan/MWCNT or chitosan/MWCNT/glucose oxidase solution, and tested versus $\mathrm{H}_{2} \mathrm{O}_{2}$ and glucose. The whole array, which measures $2.2 \times 15$ $\mathrm{mm}$, is entirely fabricated with biocompatible materials, and designed to be integrated with a CMOS chip for on-board generation of voltage ramps [12], and a multilayer coil for remote powering by inductive link [13]. The three parts together constitute the building blocks for a fully implantable device.

\section{MATERIALS AND METHODS}

\section{A. Array Microfabrication}

Microfabrication was carried out at the Centre of Micronano Technology of EPFL (CMI). Silicon wafers with $500 \mathrm{~nm}$ of native oxide were chosen as substrate. Chip metallization was realized by evaporation of $10 \mathrm{~nm}$ of Ti, followed by $100 \mathrm{~nm}$ of Pt. Metal passivation was made via atomic layer deposition of $20 \mathrm{~nm}$ of $\mathrm{Al}_{2} \mathrm{O}_{3}$. Passivation openings were made by dry etching with Argon Ion Milling.

\section{B. Sensors Functionalization}

The sensors were functionalized by electrodeposition of chitosan/MWCNT and chitosan/MWCNT/glucose oxidase dispersions. Chitosan (CHT) solution $0.7 \%$ w/v was made dissolving CHT flakes (medium molecular weight - Aldrich) in a solution of acetic acid $2 \% \mathrm{pH} 3$ and stirred until complete dissolution. Final $\mathrm{pH}$ was then set to 5. MWCNT (diameter 10 nm, lengths 1-2 $\mu \mathrm{M}, \mathrm{COOH}$ content $5 \%$ - Dropsens) were added at the concentration of $1 \mathrm{mg} / \mathrm{ml}$. The dispersion was sonicated again until homogenization. Glucose oxidase (GOx) $5 \mathrm{mg} / \mathrm{ml}$ (Sigma) was added to the mix just before the electrodeposition. To prevent hydrogen evolution at the electrode surface, $\mathrm{H}_{2} \mathrm{O}_{2} 20 \mathrm{mM}$ was added to the preparations before the electrodeposition [14]. The coating was performed applying a constant potential of $+1.5 \mathrm{~V}$ for 100,300 or 600 " to a specific working electrode, followed by a rinsing in water to remove the solution excess. The $\mathrm{pH}$ sensor was realized by electrodeposition of a solution iridium oxide ( $\mathrm{IrOx}$ ) onto a microelectrode of $250 \mu^{2}$. Details on the solution preparation 
are described by Ges et Al. [15]. Electrodeposition of IrOx was carried out applying a constant current density of 0.15 $\mathrm{mA} / \mathrm{cm}^{2}$ for 80 minutes.

\section{Measurements}

$\mathrm{H}_{2} \mathrm{O}_{2}$ and $\mathrm{pH}$ measurements were performed with an Autolab Potentiostat (Metrohm). Electrodes were tested for $\mathrm{H}_{2} \mathrm{O}_{2}$ and glucose sensitivity with chronoamperometry at +650 $\mathrm{mV}$. The sensors were first dipped in a $1 \mathrm{x}$ PBS solution $\mathrm{pH}$ 7.4 , and conditioned for 1200 " at $+900 \mathrm{mV}$, then tested against repeated injections of $\mathrm{H}_{2} \mathrm{O}_{2} 10 \mathrm{mM}$ or glucose $2 \mathrm{mM}$. For pH measurement, the array was dipped in $1 \mathrm{X}$ PBS solutions at different $\mathrm{pH}$. Before each measurement, the electrode was conditioned $45^{\prime}$ to stabilize the open circuit potential. $\mathrm{pH}$ was computed averaging the open circuit potential in a time window of 60 ". Temperature sensing was carried out by dipping the array in 1x PBS and reading the sensor resistance with a multimeter (Meterman 37XR). Temperature was gradually changed from 25 to $45^{\circ} \mathrm{C}$ with a step of $0.5^{\circ} \mathrm{C}$

\section{RESULTS AND DISCUSSION}

\section{A. Microfabrication}

Choice of materials and design was done considering biocompatibility and simplicity of fabrication as of primary importance. Only two masks resulted necessary for the whole microfabrication. As substrate, silicon has been chosen over glass for its better thermal conductibility, in order to improve the dissipation of heat generated by the integrated circuit. $\mathrm{Pt}$ metallization was chosen for three main reasons: 1) biocompatibility and resistance to corrosion, 2) pseudoreference electrode behavior, 3) employment in the fabrication of resistive thermal devices with a linear range suitable to measure physiological temperatures [16]. $\mathrm{Al}_{2} \mathrm{O}_{3}$ is a biocompatible material already used in biomedical coatings [17]. Atomic layer deposition was chosen among other techniques for its capability to generate thin, uniform and pinhole free passivations [18]. Such procedure allows improved resistance to chemical etchants: we were able to clean our sensor array up to 45 minutes in piranha solution without noticing any visible degrading of the passivation. Fig. 1 shows photographs of the microfabricated device: the platform measures $2.2 \times 15 \mathrm{~mm}$, and host five independent working electrodes (WE) with common reference (RE) and counter (CE) electrode; a pH sensor, a temperature sensor (RTD) and pads for the wire bonding of the integrated circuit. Microelectrode arrays were fabricated by creating equidistant openings on a passivated Pt surface of $1.5 \mathrm{~mm}^{2}$.

\section{B. Electrochemical cell design}

The inclusion of common reference and counter electrode, allowed simplifying the interconnections with the sensing circuitry, optimizing at the same time the available space. We realized three different WE geometries: a round electrode (diameter $500 \mu \mathrm{m}$, area 196'250 $\mu^{2}$ ), and two microelectrode arrays (diameter $10 \mu \mathrm{m}, 208$ electrodes, spacing $100 \mu \mathrm{m}$, area 17'584 $\mu^{2}$; diameter $40 \mu \mathrm{m}, 14$ electrodes, spacing $400 \mu \mathrm{m}$,

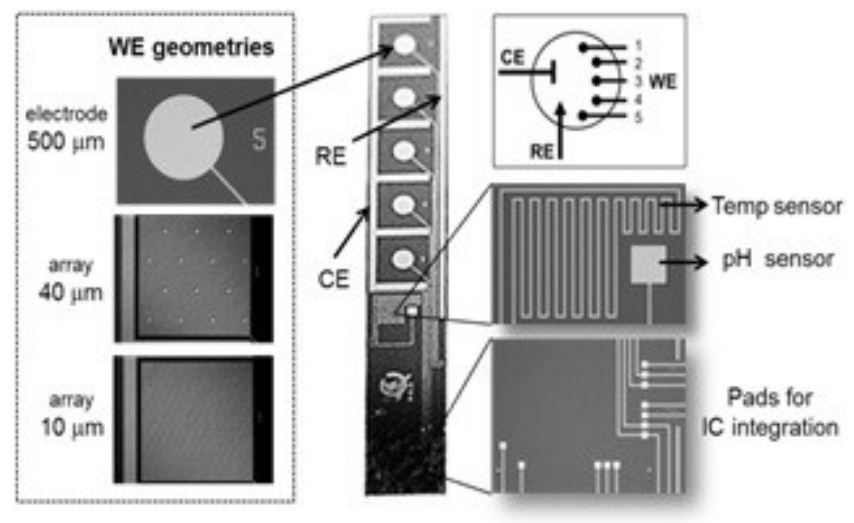

Figure 1. Photos of the microfabricated platform: left, different WE geometries; centre, whole platform $(500 \mu \mathrm{m}$ model $)$; right, temperature and $\mathrm{pH}$ sensors, pads for IC integration and schematics of the electrochemical cell.

area $17^{\prime} 584 \mu^{2}$ ). To test the various designs, we performed chronoamperometries at $+650 \mathrm{mV}$ versus $\mathrm{H}_{2} \mathrm{O}_{2}$ on the bare electrodes. Fig. 2 reports the results for each model, and a comparison with a commercial (not implantable) platinum screen printed electrode. The $10 \mu \mathrm{m}$ array provided the highest sensitivity, but also a larger variability in the results; the 40 $\mu \mathrm{m}$ array, of equivalent area, showed only the $55 \%$ of sensitivity of the $10 \mu \mathrm{m}$ array, but improved reproducibility. The $500 \mu \mathrm{m}$ electrode showed the lowest sensitivity, but values are comparable with the commercial electrode (diameter $1.4 \mathrm{~mm}$, area 1'538'600 $\mathrm{\mu m}^{2}$ ) while standard deviation is remarkably lower. We attribute this result to the more robust and reproducible fabrication process of our electrodes.

\section{Electrodes Nanostructuration}

Chitosan is a natural polysaccharide already employed in enzymes' immobilization for its biocompatibility, antibacterial properties and affinity to proteins [19]. The polarization of an electrode creates a localized region of high $\mathrm{pH}$ that can exceed chitosan's solubility limit, allowing CHT polymerization and entrapment of any other compound present in the original solution with high spatial selectivity. Fig. 3 shows the nanostructuration on the $10 \mu \mathrm{m}$ geometry for different electrodeposition times: 300,600 and 1200 " respectively on electrodes 2, 3 and 4 of the same array. Electropolymerization is localized only in proximity of the microelectrode openings. Longer times led to thicker and denser films: nanostructuration radius after 1200 " resulted to be almost the double of the one obtained after 300". Fig. 4 shows the $\mathrm{H}_{2} \mathrm{O}_{2}$ response for different depositions on the $10 \mu \mathrm{m}$ array. Sensitivities decrease, due to the chitosan insulating effect. The inclusion of conductive MWCNT permitted to recover part of the current response, but doesn't replicate bare electrode results. No appreciable differences were found between 300 and 600", while a time of 1200 " led to a decrease in the performance. The inclusion of glucose oxidase enabled the preparation of a biosensor towards a single step electrodeposition. Fig. 5 shows the response of the $500 \mu \mathrm{m}$ electrode to repeated injections of glucose $2 \mathrm{mM}$. We obtained a sensitivity of $0.09 \mathrm{pA} / \mathrm{mM} \mu \mathrm{m} 2$. Glucose detection was achieved only employing the $500 \mu \mathrm{m}$ geometry, regardless the electrodeposition time. We attribute 
this effect to the electrode area: the microelectrode arrays have a surface almost ten times smaller than the $500 \mu \mathrm{m}$ geometry, therefore the amount of immobilized enzyme is probably too low to yield appreciable $\mathrm{H}_{2} \mathrm{O}_{2}$ production.

\section{D. pH measurements}

The $\mathrm{pH}$ sensor consists in a $250 \mu \mathrm{m}^{2}$ electrode coated with an electrodeposited film of IrOx, a biocompatible material already used in the creation of implantable electrodes [20, 21]. The open circuit potential of an $\mathrm{IrOx}$ film changes in a predictable manner according to the solution $\mathrm{pH}$, and it was already exploited for the creation of $\mathrm{pH}$ sensors [22, 15]. Fig. 6 shows measurements in the $\mathrm{pH}$ range 5-8. In the considered range, the potential decreases linearly with increasing $\mathrm{pH}$. The sensor gave a sensitivity of $0.7 \mu \mathrm{V} / \mathrm{pH}$ unit $\mu \mathrm{m}^{2}$.

\section{E. Temperature measurements}

The temperature sensor consists in a Pt path of $0.02 \times 16 \mathrm{~mm}$ length. $\mathrm{Pt}$ is commonly used in the production of resistive thermal detectors (RTD). Among other metals employed in RTDs such as $\mathrm{Cu}$ and $\mathrm{Ni}$, Pt was chosen because its linear behavior in the physiological temperature range, biocompatibility, and higher metal resistivity, which allowed reducing sensor's dimensions [23].

Fig. 7 shows the response of the RTD upon different temperatures. Resistance increases linearly with temperature. Our device provided a resistance of $2.2 \mathrm{k} \Omega$ and a sensitivity of $6.8 \Omega /{ }^{\circ} \mathrm{C}$. Although the sensor succeeded to measure temperature variations in a linear fashion in the physiological range, we found that the power demand was still too high for the sensing circuitry to integrate [12]. After simulation, we established that best results are obtained increasing the resistance to $100 \mathrm{k} \Omega$. RTDs of $0.04 \times 160 \mathrm{~mm}$ can achieve this result. Further prototypes will be implemented with this solution.

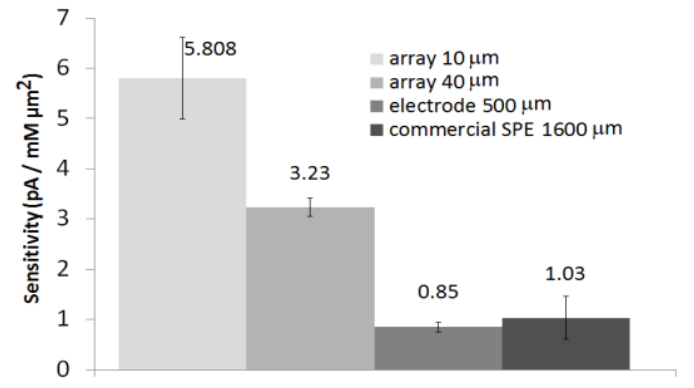

Figure 2. Sensitivities of different WE geometries to $\mathrm{H}_{2} \mathrm{O}_{2}$. Values obtained averaging 5 results. Error bars: standard deviation

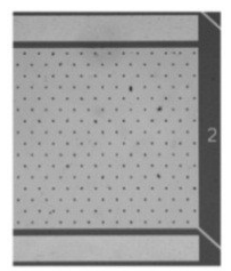

$300 "$

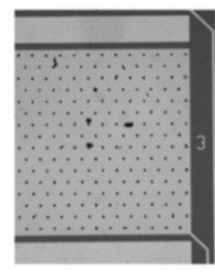

$600 "$

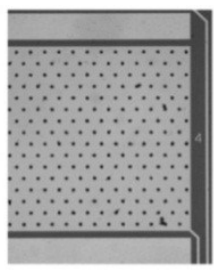

$1200 "$
Figure 3. Selective nanostructuration of the $10 \mu \mathrm{m}$ array with different electrodeposition times. Polymerization occurs only above the microelectrodes. Larger times lead to thicker and larger films.

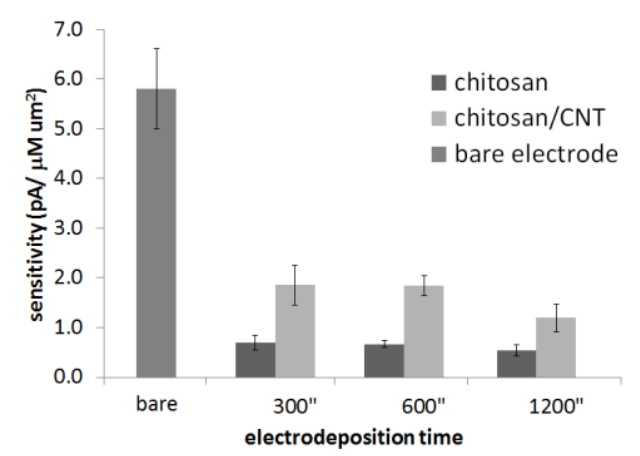

Figure $4 . \mathrm{H}_{2} \mathrm{O}_{2}$ response on the $10 \mu \mathrm{m}$ array for different kinds and times of electrodeposition. Values obtained averaging 5 measurements. Error bars, standard deviation.

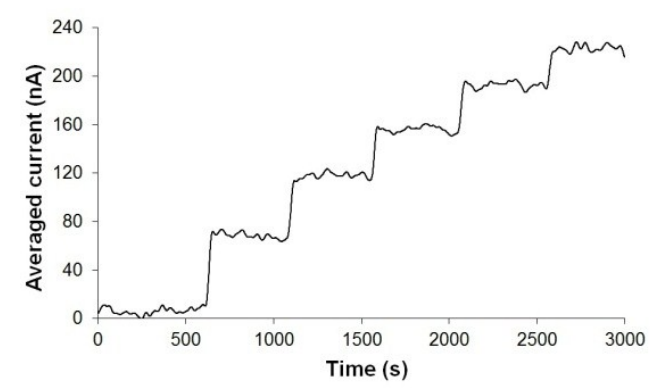

Figure 5. Glucose response of the $500 \mu \mathrm{m}$ electrode after 600 " electrodeposition of the CHT/CNT/GOx dispersion. Each step corresponds to a $2 \mathrm{mM}$ glucose injection

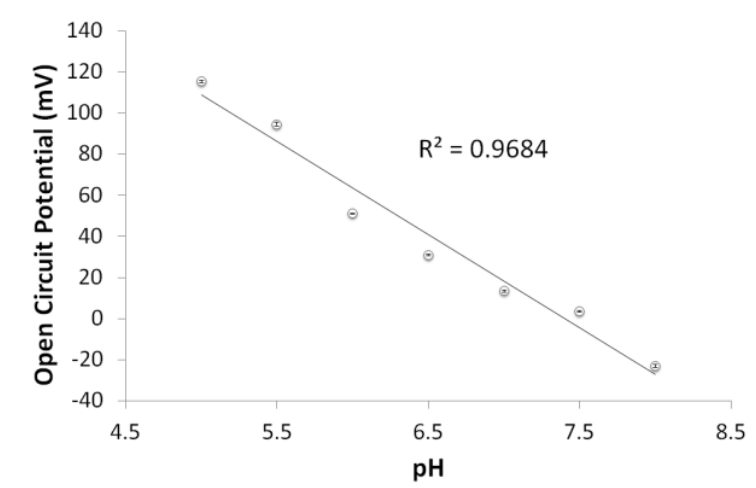

Figure 6. Open circuit potential of the IrOx coated electrode to different solutions $\mathrm{pH}$. Error bars, instrument noise

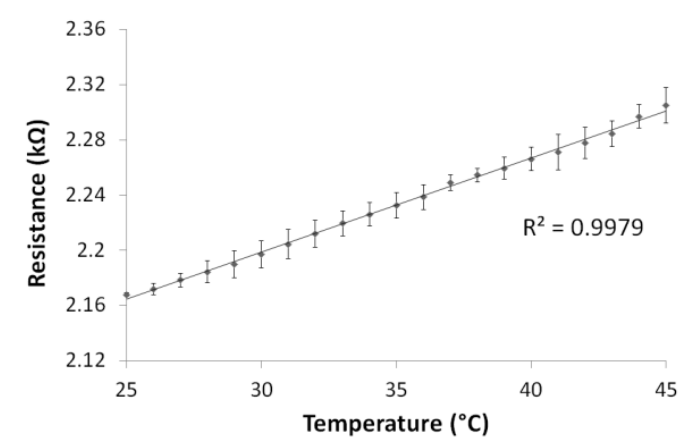

Figure 7. Resistance values of the Pt RTD at different solution temperatures. Resistance increases linearly with temperature. Error bars, average of 3 measurements. 


\section{CONCLUSIONS}

The sensor array was microfabricated considering biocompatibility, performance, robustness and simplicity of fabrication, as leading criteria for the design and the materials choice. Among tested geometries, the microelectrode arrays showed the highest response respect to $\mathrm{H}_{2} \mathrm{O}_{2}$, but resulted too small to immobilize sufficient enzyme amounts to permit glucose detection. Electrodeposition proved useful in patterning with CNTs complex geometries and conferred better resolution and uniformity respect to the drop cast. Inclusion of enzymes and CNTs in chitosan granted fast and simple preparation of biosensors in a single step electrodeposition. Selective polarization of electrodes enabled the creation of multiple biosensors on the same platform, without cross-contamination risks. The use of chitosan reduces the sensors' sensitivity, but the inclusion of CNTs allows recovering part of the original response. We conclude that chitosan's biocompatibility, antibacterial properties, selective patterning and entrapment capability confer enough advantages above the sensitivity reduction to justify its employment in implantable biosensors. Moreover, CHT and CNTs grant each other mutual benefit: chitosan is biodegradable and subject to dissolution after long permanence in solution. The inclusion of CNT improves the elastic and tensile strength of CHT, conferring more resistance. $[24,25]$. Also, the entrapment of the nanofibers in a biocompatible matrix could reduce their probability of dispersion in the body, helping to prevent potential adverse effects. The proposed solutions for $\mathrm{pH}$ and temperature sensors showed linear response in windows including the physiological range.

These results together suggest that our sensor array can be exploited for the monitoring of multiple parameters. Future work will focus on the improvement of the electrical properties of the CHT/CNT/enzyme matrix, the simultaneous sensing of different compounds, and the integration of the sensor array with the multilayer coil [13], and an updated version of the measurement circuit described in [12], capable to multiplex 5 different biosensors, the $\mathrm{pH}$ sensor and the temperature sensor, for the creation of a fully implantable platform for drug and metabolites biosensing in chronic pathologies.

\section{REFERENCES}

[1] A. Gore, S. Chakrabartty, S. Pal, and E. C. Alocilja, "A multichannel femtoampere-sensitivity potentiostat array for biosensing applications," Circuits and Systems I: Regular Papers, IEEE Transactions on, vol. 53, pp. 2357-2363, 2006

[2] R. Genov, M. Stanacevic, M. Naware, G. Cauwenberghs, and N. V. Thakor, "16-channel integrated potentiostat for distributed neurochemical sensing," Circuits and Systems I: Regular Papers, IEEE Transactions on, vol. 53, pp. 2371-2376, 2006

[3] B. Yu, N. Long, Y. Moussy, and F. Moussy, "A long-term flexible minimally-invasive implantable glucose biosensor based on an epoxyenhanced polyurethane membrane," Biosensors and Bioelectronics, vol. 21, pp. $2275-2282,2006$

[4] D. A. Gough, L. S. Kumosa, T. L. Routh, J. T. Lin, and J. Y. Lucisano, "Function of an Implanted Tissue Glucose Sensor for More than 1 Year in Animals," Science Translational Medicine, vol. 2, p. 42ra53, July 28, 20102010
[5] A. P. Li, D. L. Kaminski, and A. Rasmussen, "Substrates of human hepatic cytochrome P450 3A4," Toxicology, vol. 104, pp. 1-8, 1995.

[6] S. Carrara, M. D. Torre, A. Cavallini, D. De Venuto, and G. De Micheli, "Multiplexing $\mathrm{pH}$ and temperature in a molecular biosensor," in Biomedical Circuits and Systems Conference (BioCAS), 2010 IEEE, 2010, pp. 146-149.

[7] S. Carrara, V. V. Shumyantseva, A. I. Archakov, and B. Samorì, "Screen-printed electrodes based on carbon nanotubes and cytochrome P450scc for highly sensitive cholesterol biosensors," Biosensors and Bioelectronics, vol. 24, pp. 148-150, 2008

[8] S. Carrara, C. Boero, and G. Micheli, "Quantum dots and wires to improve enzymes-based electrochemical bio-sensing," Nano-Net, pp. 189-199, 2009.

[9] S. Carrara, A. Cavallini, V. Erokhin, and G. De Micheli, "Multi-panel drugs detection in human serum for personalized therapy," Biosensors and Bioelectronics, vol. 26, pp. 3914-3919, 2011

[10] T. J. Davies and R. G. Compton, "The cyclic and linear sweep voltammetry of regular and random arrays of microdisc electrodes: Theory," Journal of Electroanalytical Chemistry, vol. 585, pp. 63-82, 2005

[11] K. Štulík, C. Amatore, K. Holub, V. Mareček, and W. Kutner, "Microelectrodes. Definitions, characterization, and applications," Pure Appl. Chem, vol. 72, pp. 1483-1492, 2000

[12] S. S. Ghoreishizadeh, S. Carrara, and G. De Micheli, "Circuit design for human metabolites biochip," in Biomedical Circuits and Systems Conference (BioCAS), 2011 IEEE, 2011, pp. 460-463.

[13] J. Olivo, S. Carrara, G. De Micheli, "A Study of Multi-Layer Spira Inductors for Remote Powering of Implantable Sensors," Transactions on Biomedical Circuits and Systems - unpublished

[14] Q. Zhou, Q. Xie, Y. Fu, Z. Su, a. Xue'en Jia, and S. Yao, "Electrodeposition of carbon nanotubes-chitosan-glucose oxidase biosensing composite films triggered by reduction of p-benzoquinone or H2O2," The Journal of Physical Chemistry B, vol. 111, pp. 11276$11284,2007$.

[15] I. A. Ges, B. L. Ivanov, D. K. Schaffer, E. A. Lima, A. A. Werdich, and F. J. Baudenbacher, "Thin-film IrOx pH microelectrode for microfluidic-based microsystems," Biosensors and Bioelectronics, vol. 21, pp. 248-256, 2005

[16] P. R. N. Childs, J. R. Greenwood, and C. A. Long, "Review of temperature measurement," Review of Scientific Instruments, vol. 71, pp. 2959-2978, 2000.

[17] T. V. T. S. Rajeswari, "Biological Evaluation of Bioceramic Materials A Review," Trends Biomaterials Artificial Organs, vol. 18, pp. 9-17, 2004.

[18] M. Knez, K. Nielsch, and L. Niinistö, "Synthesis and Surface Engineering of Complex Nanostructures by Atomic Layer Deposition," Advanced Materials, vol. 19, pp. 3425-3438, 2007

[19] B. Krajewska, "Application of chitin- and chitosan-based materials for enzyme immobilizations: a review," Enzyme and Microbial Technology, vol. 35, pp. 126-139, 2004.

[20] W. F. Agnew, T. G. H. Yuen, D. B. McCreery, and L. A. Bullara, "Histopathologic evaluation of prolonged intracortical electrical stimulation," Experimental Neurology, vol. 92, pp. 162-185, 1986.

[21] J. D. Weiland, D. J. Anderson, and M. S. Humayun, "In vitro electrical properties for iridium oxide versus titanium nitride stimulating electrodes," Biomedical Engineering, IEEE Transactions on, vol. 49, pp. $1574-1579,2002$

[22] W. Olthuis, M. Robben, P. Bergveld, M. Bos, and W. Van Der Linden, "pH sensor properties of electrochemically grown iridium oxide," Sensors and Actuators B: Chemical, vol. 2, pp. 247-256, 1990.

[23] B. Baker, "Temperature sensing technologies," AN679, Microchip Technology Inc, 1998

[24] S. F. Wang, L. Shen, Wei-De Zhang, and, and Y. J. Tong, "Preparation and mechanical properties of chitosan/carbon nanotubes composites," Biomacromolecules, vol. 6, pp. 3067-3072, 2005

[25] Y. T. Shieh and Y. F. Yang, "Significant improvements in mechanica property and water stability of chitosan by carbon nanotubes," European polymer journal, vol. 42, pp. 3162-3170, 2006 